\title{
OCORRÊNCIA DE Hyale Grimaldii Chevreux, 1900 (CRUSTACEA AMPHIPODA HYALIDADE), NA COSTA BRASILEIRA.
}

\author{
Jeannine Maria ALVES \\ Doutoranda PPG-Oceanografia UFPE \\ Cileide Maria Acioli SOARES \\ Departamento de Oceanografia dada UFPE
}

\begin{abstract}
RESUMO
A finalidade da pesquisa é registrar uma nova ocorrência para a costa brasileira, particularmente para o litoral de Jaboatão dos Guararapes, Pernambuco. O material estudado é oriundo de coletas realizadas manualmente, em 04 estações localizadas nas Praias de Piedade, Candeias e Barra das Jangadas. O resultado da análise de 284 espécimes de 14 amostras assinalou a espécie Hyale Grimaldii Chevreux, 1900. Desse estudo conclui-se que a espécie está sendo referida pela primeira vez para a costa brasileira, e, que ecologicamente ela é costeira, comum em encraves do infralitoral ao médiolitoral, predominando em fundos de algas vivas. São considerados para a espécie, sinonímia, material examinado, distribuição geográfica, descrição e ecologia.

Palavras chave: Anphipoda, Crustacea, registro, Pernambuco, Brasil.
\end{abstract}

\section{ABSTRACT \\ Hyale grimaldii Chevreux, 1900 ( Crustacea Amphipoda Hyalidae) occurrence in the brazilian coast.}

This work presents a new occurrenceof Amphipoda Hyalidae to the brazilian coast, particulary to the coast of Jaboatão dos Guararapes, Pernambuco. The studied samples came from manual collections made in four stations located at Piedade, Candeias and Barra das Jangadas beaches. The results of 284 specimens analysed from 14 samples showed the presence of Hyale grimaldii Chevreux, 1900. It can be concluded that this especies is a new ocurrence to Brazil and that it is common in the infralittoral and in the mesolittoral imbeds, predominating on algae bottoms. It is considered the synonymy, analysed material, geographycal distribution, description and ecology for this specie.

Key words : Amphipod, Crustacea; register; Pernambuco; Brazil.

\section{INTRODUÇÃO}

Os Crustáceos Anfípodos Gamarídeos desempenham um importante papel como principais componentes macroscópicos entre os crustáceos bentônicos de várias regiões, além de constituírem elementos essenciais na teia alimentar, pois esses organismos são encontrados em quantidades apreciáveis, no conteúdo estomacal de peixes economicamente importantes (Vanucci, 1963; Soares, 1980; Soares et al, 1981; Wakabara et al, 1982 apud Soares 1986).

Atualmente a pesquisa não se detém a estudar apenas um determinado aspecto, como por exemplo, a taxonomia, mas sim visa outras informações (Biologia, Ecologia e Biogeografia), que integradas venham fornecer subsídios para um melhor entendimento dos fatores que atuam na distribuição dessas espécies e na sua distribuição geográfica.

Trab. Oceanog. Univ. Fed. PE, Recife, 28(1): 61- 70, 2000. 
O presente trabalho constitui um levantamento dos Crustáceos Anfípodos Gamarídeos da família Hyalidae que ocorreram no período de julho/88 e junho/89 no litoral de Jaboatão dos Guararapes - Pernambuco.

A pesquisa tem como finalidade, o estudo taxonômico a nível de família, gêneros e espécies, bem como, aspectos biológicos, ecológicos e distribuição geográfica.

\section{DESCRIÇÃO DA ÁREA}

A vila de Jaboatão dos Guararapes foi criada em 24 de maio de 1873 e foi elevada à categoria de cidade em 27 de junho de 1884, tornando-se município autônomo em 03 de agosto de 1892. Esse município localiza-se na zona fisiográfica da mata e pertence a região metropolitana do Recife, tendo uma área de $234 \mathrm{Km}^{2}$, a sua sede situa-se a $08^{\circ} 10^{\prime} 00^{\prime \prime S}$ e $35^{\circ} 08^{\prime} 00^{\prime \prime} \mathrm{W}$.

O seu litoral é constituído por praias contínuas sendo elas: Piedade, Candeias e Barra de Jangadas. Essas praias foram divididas em estações.

O litoral de Jaboatão, possui o clima do tipo Ams, quente e úmido, com temperatura média próxima a $26^{\circ} \mathrm{C}$ e uma precipitação média anual em torno de $1.720 \mathrm{~mm}$ (FIDEM, 1982).

Segundo Cavalcanti e Kempf (1970), nessa região há predominância de ventos alíseos no período de outubro a março e de Sul- sudeste, no período de abril a setembro.

Os dados hidrológicos registraram uma média anual de temperatura da água nessa área em torno de $28^{\circ} \mathrm{C}$, e a salinidade entre $32,00^{\circ} / 00$ e $36,00^{\circ} / 00$, correspondendo respectivamente ao período chuvoso e seco (Cavalcanti e Kempf, 1970). As variações de salinidade em zonas costeiras são influenciadas pelas marés e pela precipitação. Segundo Costa et al (1989) apud Barreto e Alves (1989), parâmetros físicos e químicos da área estudada, apresentam grande influência terrígena, principalmente do Rio Jaboatão, que se manifesta mais intensamente no período chuvoso. As praias em estudo sofrem influência deste rio, que deságua na Praia da Barra das Jangadas.

Segundo FIDEM (1979) a forma de relevo dominante é a planície costeira, que compreende toda a faixa litorânea, possuindo relevo plano ondulado. Encontram-se, também como forma de relevo, colinas com cumes arredondados e encostas suaves com altitudes em torno de 80 metros.

A vegetação deste município é composta de 2 tipos: vegetação nativa e vegetação cultivada. A primeira é formada pela capoeirinha, capoeira, capoeirão e mangue. E a segunda é formada pelas culturas de subsistência da área - a cana de açúcar e o coco (FIDEM, 1979).

Segundo o Censo Demográfico de 1980 realizado pelo IBGE, a população do Distrito de Muribeca dos Guararapes, onde está situado o litoral de Jaboatão, cresceu 25.390 habitantes, no ano 1960, passando para 158.327 no ano de 1980.

\section{MATERIAL E MÉTODOS}

O material estudado provém de coletas realizadas na Praia de Piedade, desde o Hotel Barramares até o Restaurante Canto da Barra na Praia de Barra de 
Jangadas, Jaboatão - Pernambuco. As coletas foram realizadas mensalmente, nas baixas-marés diurnas, em quatro estações previamente delimitadas (Figura 1).

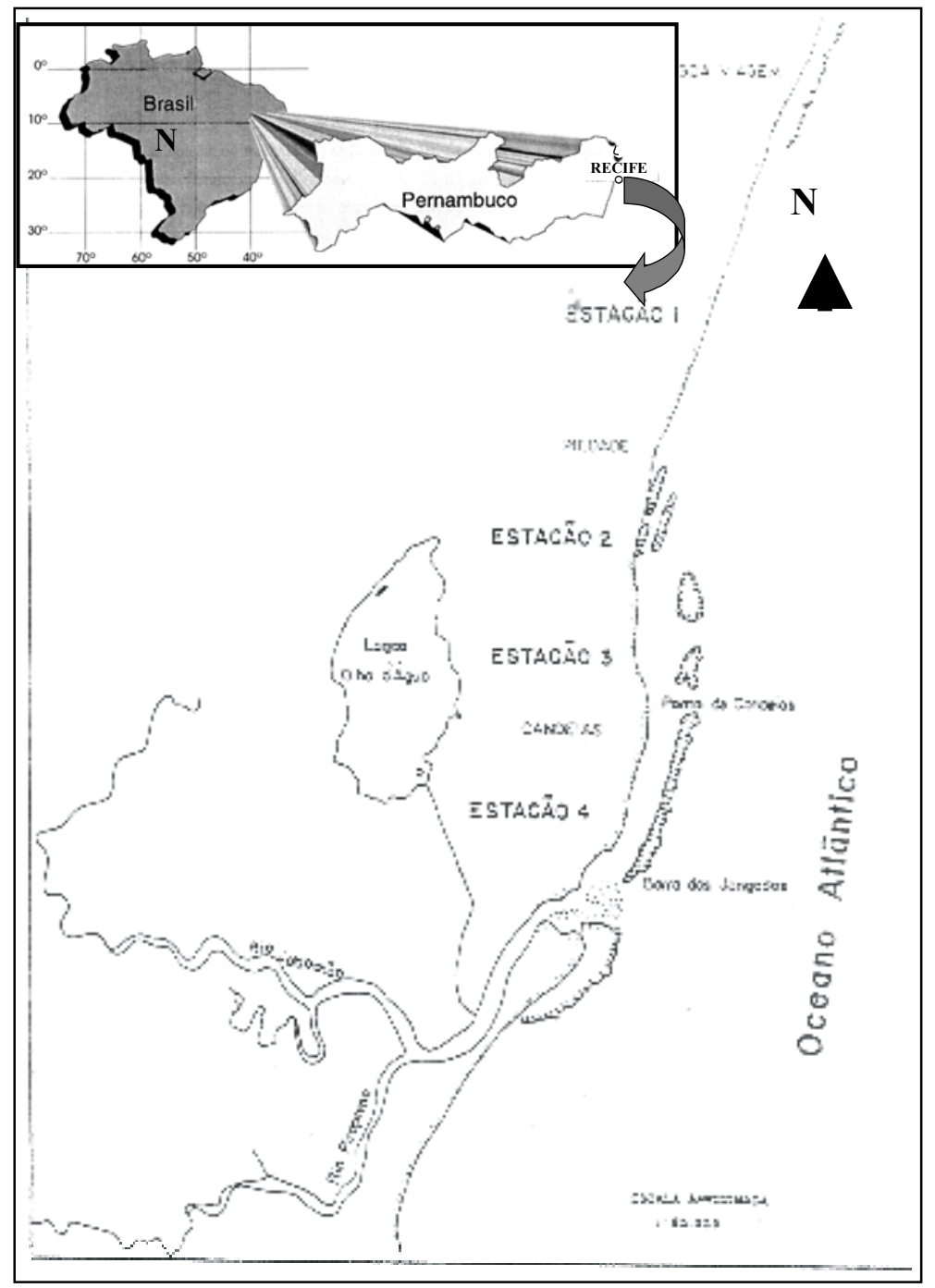

Figura I. Mapa da área representando as estações de coleta no litoral de Jaboatão-PE 
A estação 1 situa-se a $08^{\circ} 10^{\prime} \mathrm{S}$ e $34^{\circ} 55^{\prime} \mathrm{W}$ e faz limite com a última praia do município do Recife. Não possui formação de arrecifes emergindo à baixa-mar. A estação 2 localiza-se a $08^{\circ} 10^{\prime} 38^{\prime \prime S}$ e 3454'57'W. O local é caracterizado por suas formações de recifes compostos por um banco de arenito calcáreo oblíquo em relação ao litoral, constituindo uma espécies de dique natural. Esta formação calcária é recoberta pelas águas durante a maré-alta e nas baixas-marés torna-se parcialmente emersa formando uma pequena lagoa (Laborel e Kempf, 1965). A estação 3 situa-se a $08^{\circ} 11^{\prime}$ 'S e $34^{\circ} 56^{\prime} \mathrm{W}$, não possuindo formação de recifes. Esta constitui em desembarque de pesca de altomar. A estação 4 localiza-se a $08^{\circ} 12^{\prime} \mathrm{S}$ e $34^{\circ} 55^{\prime} \mathrm{W}$. Essa é mais próxima da desembocadura do Rio Jaboatão, conseqüentemente suas águas estão na maioria das vezes turvas e sua salinidade sempre variando. Possui uma formação de recife constituído por bancos de algas calcárias emergindo à baixa-mar e localizados a uma certa distância da praia, também na baixa-mar há formações de extensos bancos de areia.

O material foi obtido através de coletas manuais ou com o auxílio de redes de arrasto e foram colocados em recipientes de vidro. Em seguida, as amostras foram acondicionadas em vidros devidamente etiquetados e fixadas em álcool a 75\%. No laboratório, os espécimens foram examinados e identificados com o auxílio de uma lupa ZEISS e microscópio composto. A identificação das espécies se fez através da dissecação do animal, com auxílio de pinças, estiletes e preparação de lâminas para análise ao microscópio. Paralelamente, realizou-se contagem, separação de machos e fêmeas, medição dos espécimens em placa milimetrada.

Os dados ecológicos foram registrados durante as coletas e analisados, levando-se em consideração o tipo de fundo, a salinidade e a temperatura da água. $\mathrm{Na}$ identificação das espécies, utilizou-se bibliografias especializadas contendo chaves sistemáticas baseadas, principalmente, em Griffiths (1976) e Barnard $(1965,1969)$ e por comparação com formas semelhantes em descrição na literatura de Chevreux e Fage (1925), Barnard e Karaman (1991). A sinonímia da espécie está de acordo com Mcgrath e Myers (1989).

\section{Hyale grimaldii Chevreux, 1900}

\section{RESULTADOS}

Hyale grimaldii Chevreux, 1981:257; 1900:10; Stebbing, 1906: 567, 736;

Chevreux e Fage, 1926: 285; Buycheva, 1957: 93. Giovannini, 1965: 296; Mateus e Afonso. $1974: 16$.

Hyale prevosti Stebbing, 1988: 144; Della Valle; 1893: 889 (não Hyale prevosti Milne Edwards; 1830: 378)

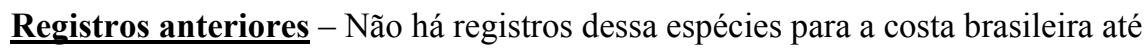
o momento.

Material examinado - Foram identificadas 284 espécimens, procedentes de

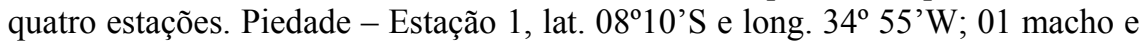


01 fêmea em 30/08/88; 01 macho em 05/04/89. Estação 2, lat. 08¹0'38'S e long. 3454'57'W; 07 machos e 22 fêmeas em 28/09/89; 06 machos e 09 fêmeas em 23/10/88; 26 machos e 65 fêmeas em 29/08/88; 06 machos e 08 fêmeas em 29/07/89; 02 machos e 04 fêmeas em 27/09/88; 04 machos e 19 fêmeas em 01/08/88; 05 machos e 07 fêmeas em 01/07/88; 02 machos em 10/01/89; 16 machos e 54 fêmeas em 08/11/88. Estação 3, lat. 08 ${ }^{\circ} 11^{\prime}$ S e long. 34 $56^{\circ} \mathrm{W} ; 02$ machos e 01 fêmea em 06/04/89. Barra de Jangadas - Estação 4, lat. 08 12 'S e long. $34^{\circ} 55^{\prime} \mathrm{W}$; 06 machos e 08 fêmeas em 28/08/88; 01 macho em 26/09/88 e 01 fêmea em 02/07/88.

Distribuição Geográfica - No Mar Mediterrâneo, Atlântico Norte (Chevreux e Fage, 1925), Açores, Portugal, Irlanda, Península Ibérica, Estreito de Gibraltar, Norte da África Macgrath e Myers, (1989); Lopes, Marques e Bellan- Santini (1993) e Atlântico Oriental ( Barnard e Karaman, 1991) e Atlântico Ocidental, Pernambuco - Brasil

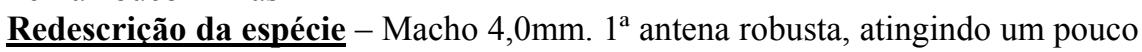
mais da metade do flagelo da $2^{\mathrm{a}}$ antena, pedúnculo com 3 artículos e flagelo com 10 artículos; $2^{\mathrm{a}}$ antena não muito robusta, menor do que a metade do corpo, pedúnculo com 3 artículos e flagelo com 14 artículos; olhos negros, ovais; $1^{\circ}$ gnatópodo menor e mais delgado do que o $2^{\circ} ; 6^{\circ}$ artículo do $1^{\circ}$ gnatópodo liso na margem anterior, borda da palma transversa, borda posterior com espinhos, dáctilo curvo ultrapassando a borda palma, $2^{\circ}$ gnatópodo, grande e robusto, borda da palma com um processo junto do dáctilo; placas coxais arredondadas; dáctilos do $1^{\circ}$ ao $5^{\circ}$ pereópodo lisos; $5^{\circ}$ pereópodo com articulação basal mais larga do que longa, borda posterior um pouco serrilhada; $6^{\circ}$ artículo dos $4^{\circ}$ e $5^{\circ}$ pereópodos lisos posteriormente; $3^{\circ}$ urópodo com um ramo; telso mais largo do que longo e profundamente clivado. Fêmea ovada (4 ovos), $1^{\text {a }}$ antena um pouco maior do que o pendúculo da $2^{\mathrm{a}}$ antena, pendúculo com 2 artículos e flagelo com 9 artículos; pedúnculo da $2^{\mathrm{a}}$ antena com 4 artículos e flagelo com 15 artículos; $1^{\mathrm{o}}$ gnatópodo com o corpo ligeiramente dilatado, borda da palma transversa; 2 gnatópodo quase do mesmo tamanho do 1; própodo dos pereópodos do 1 ao 5 com cerdas (Estampas 1,2,3 e 4).

Dimensões - Para os espécimens machos, o comprimento variou entre $2,0 \mathrm{~mm}$ a $5,0 \mathrm{~mm}$ e as fêmeas entre $1,0 \mathrm{~mm}$ a $5,0 \mathrm{~mm}$.

Ecologia - Chevreux e Fage (1925) estudando os anfípodos da fauna da França, encontrou a espécie Hyale grimaldii em algas sobre tartarugas marinhas no Mediterrâneo e Atlântico Norte. Para o litoral de Jaboatão - Pernambuco, a espécie foi encontrada em fundos de algas e em águas rasas.

Os parâmetros físico-químicos assinalados são: Estação 1 de $25^{\circ} \mathrm{C}$ a $31^{\circ} \mathrm{C}$ a variação de salinidade ficou entre $32,30^{\circ} / 00$ a $37,39^{\circ} / 00$ e a temperatura da água em $25^{\circ} \mathrm{C}$ a $31,{ }^{\circ} \mathrm{C}$; Para a estação 2 , a salinidade variou de $21,62^{\circ} / 00$ a $37,39^{\circ} / 00$ e a temperatura da água entre $25,{ }^{\circ} \mathrm{C}$ a $33,{ }^{\circ} \mathrm{C}$; a estação 3 , a salinidade variou de $30,55^{\circ} / 00$ a $36,88^{\circ} / 00$ e a temperatura da água entre $25,{ }^{\circ} \mathrm{C}$ a $32,{ }^{\circ} \mathrm{C}$ e finalmente para a estação 4 a salinidade variou de $22,70^{\circ} / 00$ a $35,00^{\circ} / 00$ e a temperatura da água entre $24,{ }^{\circ} \mathrm{C}$ a $34,5^{\circ} \mathrm{C}$.

Análise geral dos indivíduos da Família Hyalidae, em função do período estudado. Analisando a figura 2, observou-se que para as estações estudadas, o 
número de indivíduos atingiu o seu valor máximo no mês de agosto/88 caindo bruscamente no mês seguinte, em novembro/ 88 houve um pequeno acréscimo. Nos meses de fevereiro/89 a junho/89 não houve registros de espécimens.

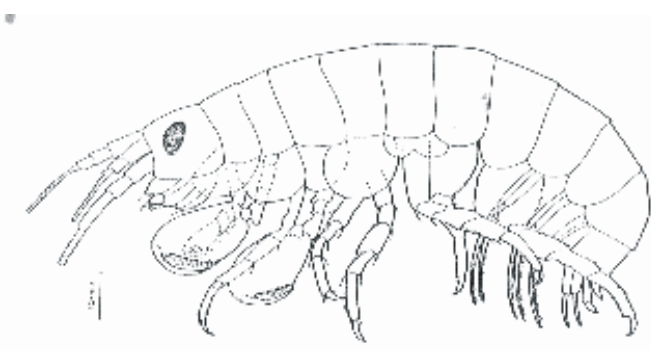

ESTAMPA I Hyle grimaldii Chevreux, 1900

Morfologia externa, macho 5,0mm (Original)

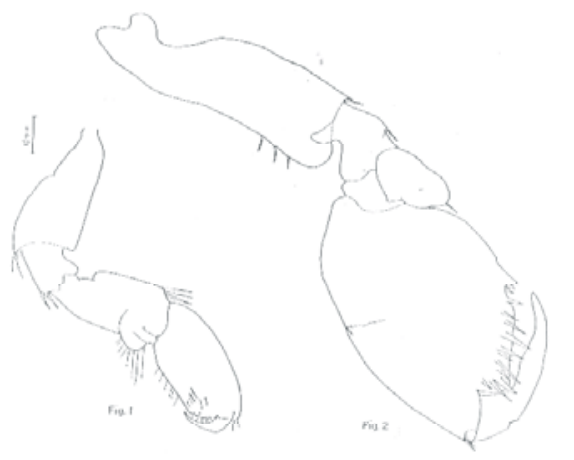

ESTAMPA 2 Hyle grimaldii Chevreux, 1900.

Fig. I e 2 respectivamente, $1^{\circ}$ e $2^{\circ}$ gnatópodo do macho.(Original) 


\section{DISCUSSÃO}

O material estudado nesta pesquisa, está representado por uma família, um gênero e uma espécie. $\mathrm{O}$ estudo taxonômico do gênero e espécie permitiu a análise das particularidades existentes em cada um desses taxa.

A análise das amostras, registrou o gênero Hyale Rathke, 1837 que confere com a descrição de Barnard (1969). A determinação da espécie Hyale grimaldii Chevreux, 1900, está de acordo com Chevreux e Fage (1925) e Barnard e Karaman (1991), destacando os seguintes caracteres: O segundo gnatópodo possui um processo palmar junto do dáctilo; dáctilos do primeiro ao quinto pereópodos lisos; quinto pereópodo com articulação basal mais larga do que longa, borda posterior ligeiramente serrilhada; terceiro urópodo com ramo e telso profundamente clivado.

No que se refere à ecologia, os dados relativos aos parâmetros hidrológicos registraram uma média anual de temperatura da água em torno de $28^{\circ} \mathrm{C}$, com variações para cada estação. A salinidade da água ficou entre $32,00 \%$ e e 36,0\% $\%$, correspondendo, respectivamente, ao período chuvoso e seco, também com oscilações para cada estação.

Com relação a distribuição vertical, as espécies são costeiras e de águas rasas, comuns em substratos de algas. 


\section{CONCLUSÕES}

Do total de 284 espécimens analisados, verificou-se a ocorrência de um gênero e uma espécie para a família Hyalidae. brasileira.

A espécie Hyale grimaldii é referida pela primeira vez para a costa

Quanto a distribuição batimétrica da espécie estudada, estabeleceu-se que a mesma é costeira, comum nos encraves do infra no médiolitoral.

A natureza do substrato exerce uma certa influência na distribuição das populações dos anfípodos. Por essa razão, a espécie é predominantemente de fundos de algas.

\section{REFERÊNCIAS BIBLIOGRÁFICAS}

BARNARD, S.L. 1965. Proceedings of the United State National Museum. Marine Amphipoda of Atolls in Micronesia, Washington, v.7, n.35 16, p.459-552.

1969. The families and genera of Marine Gammaridean Amphipoda. Washington: Smithsonian Institutions, 535 p.

BARNARD, J. L.; KARAMAN, G. S. 1991. The families and genera of marine Gammaridean Amphipoda (except marine Gammaridea). Rev. Aust. Mus., Ireland, suppl. 13, part $1 / 2,866$ p.

BARRETO, A.V., ALVES, M.S. 1989. Povoamentos Bentônicos Costeiros da Praia de Piedade - PE. Recife, 34p. Relatório de atividades referente a disciplina Bionomia Bêntica Marinha. (Mestrado em Oceanografia). Departamento de Oceanografia, Universidade Federal de Pernambuco.

CAVALCANTI, L.B., KEMPF, M. 1970. Estudo da plataforma continental da área do Recife (Brasil). II. Meteorologia e Hidrologia. Trabalhos Oceanográficos da Universidade Federal de Pernambuco. Recife, v. 9/11, p. 149-159.

CHEVREUX, E., FAGE, L. 1925. Faune de France - Amphipodes. Paris: Lechevalier, p.280-289.

FUNDAÇÃO DE DESENVOLVIMENTO DA REGIÃO METROPOLITANA DO RECIFE. 1979. Mapeamento temático da cobertura vegetal da Região Metropolitana do Recife. Recife, 100p.

FUNDAÇÃO DE INFORMAÇÃO PARA O DESENVOLVIMENTO DE PERNAMBUCO. 1976. Informações Municipais - Jaboatão. Recife, $1982.5 \mathrm{p}$.

GRIFFITHS, $C$. Guide to the benthic Marine Amphipoda of Southern África. Cape Town: South African Museum, 106p.

LABOREL, S.L., KEMPF, M. 1965. Formações de vermentos e algas calcárias na costa do Brasil. Trabalhos Oceanográficos da Universidade Federal de Pernambuco. Recife, v. 7/8, p. 33-50 .

LOPES, M.F.R. et al. 1993. The benthic amphipod fauna of the Azores (Portugal): na up-to-date annotated list of species, and some biogeographic considerations. Crustaceana, Leiden, v. 65, n. 2, p. 204-217.

MCGRATH, D., MYERS, A.A. 1989. The Drift Amphipod Hyale grimaldii in Irish and British Waters. JMBA: Great Britain. v. 69, n. 4. 
SOARES, C.M.A. 1986. Crustáceos Anfipodos do Brasil: Família

Gammaridae. Recife, 1986. 197 p. Dissertação (Mestrado em Oceanografia). Universidade Federal de Pernambuco. 